\title{
EVALUASI SISTEM DRAINASE KOTA DAN KABUPATEN SORONG
}

\author{
Frisca Natalia Matwear ${ }^{1)}$ \\ ${ }^{1)}$ Program Studi Teknik Sipil Universitas Muhammadiyah Sorong \\ Jalan Pendidikan No 27 Kota Sorong, Provinsi Papua Barat \\ Email : friscamatwear926@ gmail.com
}

\begin{abstract}
ABSTRAK
Drainase merupakan salah satu fasilitas dasar yang dirancang sebagai sistem guna memenuhi kebutuhan masyarakat dan merupakan komponen penting dalam perencanaan Kota dan Kabupaten Sorong. Prasarana drainase disini berfungsi untuk mengalirkan air permukaan ke badan air (sumber air permukaan dan bawah permkaan tanah) dan atau bangunan resapan. Semakin berkembangnya suatu daerah, lahan kosong untuk meresapkan air secara alami akan semakin berkurang. Permukaan tanah tertutup oleh beton dan aspal, hal ini akan menambah kelebihan air yang tidak terbuang. Kelebihan air ini jika tidak dapat dialirkan akan menyebabkan genangan. Dalam perencanaan saluran drainase harus memperhatikan tata guna lahan daerah tangkapan air saluran drainase yang bertujuan menjaga ruas jalan tetap kering walaupun terjadi kelebihan air, sehingga air permukaan tetap terkontrol dan tidak mengganggu pengguna jalan.
\end{abstract}

Kata Kunci : Drainase, Iirigasi, Rruas jalan 


\section{PENDAHULUAN}

Pada umumnya saluran drainase jalan raya adalah saluran terbuka dengan menggunakan gaya gravitasi untuk mengalirkan air menuju ke dasar terrendah. Saluran drainase adalah salah satu bangunan pelengkap pada ruas jalan dalam memenuhi salah satu persyaratan teknis prasarana jalan. Saluran drainase jalan raya berfungsi untuk mengalirkan air yang dapat mengganggu pengguna jalan, sehingga badan jalan tetap kering. Saat ini sistem drainase sudah menjadi salah satu infrastruktur yang sangat penting. Kualitas manajemen dapat dilihat dari kualitas sistem drainase yang ada. Sistem drainase yang baik dapat membebaskan kota dari genangan air. Genangan air menyebabkan lingkungan menjadi kotor dan jorok, menjadi sarang nyamuk, dan sumber penyakit lainnya, sehingga dapat menurunkan kualitas lingkungan, dan kesehatan masyarakat. Genangan di ruas jalan masih sering terjadi di Kota dan Kabupaten Sorong. Genangan di ruas jalan akan mengganggu masyarakat yang menggunakan ruas jalan tersebut untuk melakukan aktivitas.

\section{METODOLOGI}

Lokasi Studi

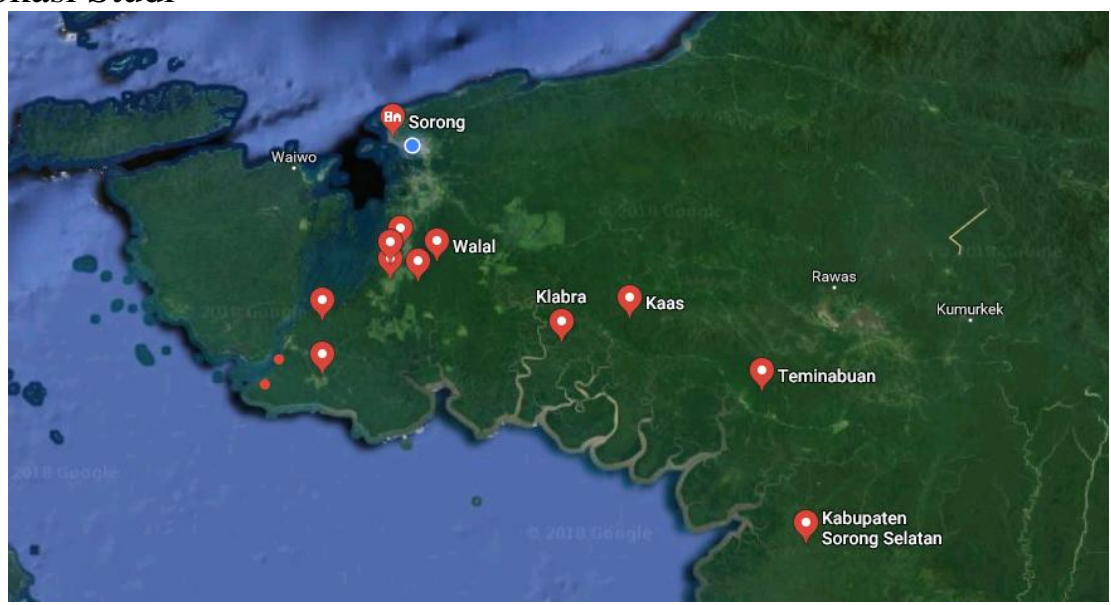

Gambar 1. Lokasi Studi

Tahapan penyusunan artikel :

1. Penelitian tema artikel

2. Penelusuran artikel yang bersesuaian dengan tema yang kita ambil (melalui google scholar)

3. Apabila komparasit terhadap artikel yang didapatkan dari google scholar

4. Membuat kesimpulan untuk menjawab tujuan penulisan artikel

Semua metode penulisan dan analisa dalam artikel ilmiah ini merujuk pada panduan penulisan tugas akhir Fakultas Teknik Universitas Muhammadiyah Sorong tahun 2014 (Pristianto, Amri, \& Rusdi, 2014). 


\section{HASIL DAN PEMBAHASAN}

\section{Penelitian dengan tema yang sama.}

Beberapa hasil penelitian terkait tema artikel ini adalah sebagai berikut :

1. Fauzan, A., \& Pristianto, H. (2017). STUDI KELAYAKAN KAPASITAS TAMPUNG DRAINASE JALAN FRANS KAISEPO KELURAHAN MALAINGKEDI KOTA SORONG. RANCANG BANGUN, 3(1), kesimpulan yang dapat di ambil dari uraian ini adalah :

Pada kondisi saat ini untuk kelayakan kapasitas tampung drainase jalan Frans Kaisepo, pada ruas kanan dan kiri tidak mampu menampung debit banjir periode ulang 2, 5, dan 10 dengan penampang drainase bersedimentasi. Setelah dianalisa penampang drainase dianggap tidak bersedimentasi untuk kelayakan kapasitas tampung drainase pada ruas kanan bisa menampung debit periode ulang 2, 5 dan 10 Thn. Pada ruas kiri masih mampu menampung debit banjir periode ulang 2 Th. tetapi tidak bisa menampung debit banjir periode ulang 5 dan 10 Th.

Kondisi Drainase di sepanjang Jalan Frans Kaisepo adalah pada kondisi yang diasumsi tidak bersedimentasi kondisi optimalnya adalah:

a. Saluran kanan hanya mampu menampung sekitar $92,81 \%$ sedangkan saluran kiri menampung 73,31\% limpasan permukaan akibat intensitas hujan periode ulang 2 tahun dari masing masing catchment area-nya

b. Saluran kanan hanya mampu menampung sekitar $72,05 \%$ sedangkan saluran kiri menampung 56,91\% limpasan permukaan akibat intensitas hujan periode ulang 5 tahun dari masing masing catchment area-nya

c. Saluran kanan hanya mampu menampung sekitar $63,10 \%$ sedangkan saluran kanan menampung $49.08 \%$ limpasan permukaan akibat intensitas hujan periode ulang 10 tahun dari masing masing catchment area-nya

1. Hasil perhitungan debit saluran untuk debit banjir periode ulang dengan menggunakan metode Rasional untuk ruas jalan Frans Kaisepo di dapat :

Ruas kanan : Q2th = $2.82 \mathrm{~m} 3 / \mathrm{dtk}, \mathrm{Q} 5 \mathrm{th}=3.64 \mathrm{~m} 3 / \mathrm{dtk}$, dan Q10th = 4.15 $\mathrm{m} 3 / \mathrm{dtk}$

Ruas kiri $\quad$ : Q2th $=4.33 \mathrm{~m} 3 / \mathrm{dtk}, \mathrm{Q} 5 \mathrm{th}=5.58 \mathrm{~m} 3 / \mathrm{dtk}$, dan Q10th $=6.37$ $\mathrm{m} 3 / \mathrm{dtk}$

Dari debit banjir periode ulang yang diperoleh dari analisa perhitungan, maka terjadinya banjir dilapangan diakibatkan oleh kapasitas tampung yang tidak memadai karena tingginya sedimentasi yang ada pada drainase baik ruas kanan dan kiri jalan Frans Kaisepo.

Oleh karena itu perlu adanya pengerukan sedimentasi agar drainase bisa menampung kapasitas debit banjir periode ulang Q2, Q5 dan Q10 pada saluran drainase ruas kanan.. Untuk saluran ruas kiri jika sedimentasi dikeruk hanya mampu menampung kapasitas debit banjir periode ulang Q2. Setelah dianalisa dengan alternatif desain untuk Q5 dan Q10 pada saluran ruas kiri maka bisa menampung debit banjir apabila:

a. Untuk dimensi penampang periode ulang Q5th adalah:

Lebar dasar saluran (B)

$$
\begin{aligned}
& =1.80 \mathrm{~m} \\
& \text { Tinggi Aliran }(\mathrm{h}) \\
& =1.40 \mathrm{~m} \\
& \text { Tinggi jagaan }(\mathrm{F}) \\
& =0.24 \mathrm{~m}
\end{aligned}
$$


Kemiringan ijin saluarn

$=0.0031$

Koefisien kekasaran Manning

$=0.02$

Kemiringn talud (m)

$=0.16$

b. Untuk dimensi penampang periode ulang Q10th adalah:

Lebar dasar saluran (B)

$=1.85 \mathrm{~m}$

Tinggi Aliran (h)

$=1.50 \mathrm{~m}$

Tinggi jagaan $(\mathrm{F})$

$=0.24 \mathrm{~m}$

Kemiringan ijin saluarn

$=0.0031$

Koefisien kekasaran Manning

$=0.02$

Kemiringn talud $(\mathrm{m})$

$=0.16$

2. Menurut Wardoyo (2017) yang meneliti tentang Tinjauan Sistem Drainase Jalan Gabus Dan Jalan Tawes Tugu Merah Kabupaten Sorong, kesimpulan yang dapat di ambil dari uraian ini adalah :

Berdasarkan hasil analisis pada bab pembahasan yang telah dilakukan sebelumnya maka dapat ditarik suatu kesimpulan :

1. Pada kondisi saat ini untuk kapasitas tampung saluran jalan Gabus dan jalan Tawes baik pada ruas kanan dan kiri perlu di lakukan perhitungan kembali dalam perencanaan desain penampang baru, karena pada dasarnya penampang saluran sudah tidak dapat menampung debit banjir periode ulang 2, 5 dan 10 tahun baik pada awal pelaksanaan maupun pada kondisi riil yang ada pada saat ini. Jika dilihat efiensi kapasitas tampungnya pada kondisi riil ini adalah :

- Akibat intensitas hujan periode ulang 2 tahun, saluran gabus kanan hanya mampu menampung sekitar $65,95 \%$ sedangkan saluran gabus kiri, gabus tawes kanan dan tawes kiri mampu menampung debit lipasan permmukaan.

- Akibat intensitas hujan periode ulang 5 tahun, saluran gabus kanan hanya mampu menampung sekitar 52,95\% dan saluran kiri hanya mampu menampung $81,15 \%$ sedangka saluran tawes kanan dan tawes kiri mampu menampung debit limpasan permukaan.

- Akibat intensitas hujan periode 10 tanun, saluran gabus kanan hanya mampu menampung sekitar 47,08 \% dan saluran gabus kiri hanya mampu menampung 72,48 \% sedangkan saluran tawes kan dan tawes kiri ma,pu menampung debit limpasan permukaan.

2. Hasil perhitungan debit saluran untuk debit banjir periode ulang dengan menggunakan periode Rasional di dapat :

a. Untuk ruas jalan gabus

- Ruas kanan : $\mathrm{Q}_{2}=2.52 \mathrm{~m}^{3} / \mathrm{dtk}, \mathrm{Q}_{5}=3.14 \mathrm{~m}^{3} / \mathrm{dtk}$ dan $\mathrm{Q}_{10}=3,53 \mathrm{~m}^{3} / \mathrm{dtk}$.

- Ruas Kiri : $Q_{2}=1,67 \mathrm{~m}^{3} / \mathrm{dtk}, \mathrm{Q}_{5}=2,09 \mathrm{~m}^{3} / \mathrm{dtk}$ dan $\mathrm{Q}_{10}=2,34 \mathrm{~m}^{3} / \mathrm{dtk}$.

b. Untuk ruas jalan Tawes

- Ruas kanan : $\mathrm{Q}_{2}=0,98 \mathrm{~m}^{3} / \mathrm{dtk}, \mathrm{Q}_{5}=1,23 \mathrm{~m}^{3} / \mathrm{dtk}$ dan $\mathrm{Q}_{10}=1,38 \mathrm{~m}^{3} / \mathrm{dtk}$.

- Ruas Kiri : $\mathrm{Q}_{2}=0,75 \mathrm{~m}^{3} / \mathrm{dtk}, \mathrm{Q}_{5}=0,94 \mathrm{~m}^{3} / \mathrm{dtk}$ dan $\mathrm{Q}_{10}=1,05 \mathrm{~m}^{3} / \mathrm{dtk}$. 
Dari hasil perhitungan debit banjir periode ualang yang diperoleh, maka luapan air terjadi pada penampang saluran gabus ruas kanan dan ruas kiri, diakibatkan oleh kapasitas tampungnya yang tidak memadai. Sengkan pada saluran tawes ruas kanan dan ruas kiri dapat menampung luapan air.

3. Perencanaan dimensi penampang pada saluran gabus kanan dan saluran gabus kiri, serta saluran tawes kanan dan tawes kiri.

a. Saluran gabus ruas kanan

- Tinggi saluran $\mathrm{H}=1,80 \mathrm{~m}$

- Lebar atas $\quad \mathrm{La}=1.90 \mathrm{~m}$

- Lebar bawah $\quad \mathrm{Lb}=1.52 \mathrm{~m}$

- Dasr saluran $\quad=+18.55$

- $\mathrm{Q} 2=+19.337, \mathrm{Q} 5=+19.539, \mathrm{Q} 10=+19.666$

b. Saluran Tawes ruas kanan

- Tinggi saluran $\quad \mathrm{H}=1,02 \mathrm{~m}$

- Lebar atas $\quad \mathrm{La}=1.70 \mathrm{~m}$

- Lebar bawah $\quad \mathrm{Lb}=1.52 \mathrm{~m}$

- Dasr saluran $\quad=+19.60$

- $\quad \mathrm{Q} 2=+19.963, \mathrm{Q} 5=+20.115, \mathrm{Q} 10=+20.206$

4. Setelah melakukan perhitungan Rencana Anggaran Biaya (RAB), anggaran yang di dipat yaitu Satu Miliar Sembilan Ratus Empat Juta Enam Ratus Ribu Rupiah.

3. Menurut Pristianti H (2018) yang meneliti tentang Identifikasi Tinggi Genangan Banjir Di Das Remu Berdasarkan Kejadian Banjir Tahun 20062008, kesimpulan yang dapat di ambil dari uraian ini adalah :

1. Dari data yang diperoleh dan dari hasil plotting tinggi genangan pada peta, didapatkan pola penurunan tinggi genangan pada titik-titik daerah yang diteliti dari tahun 2006 ke tahun 2008. Sehingga dapat diketahui bahwa pada kejadian banjir 3 tahun tersebut (2006-2008) yang terbesar adalah pada kejadian banjir tahun 2006.

2. Penurunan ini disebabkan karena adanya pengerukan dasar sungai pada lokasi tersebut, sehingga penampang banjir sungai dapat menampung debit banjir sungai Remu.

3. Akan tetapi hal tersebut tidak akan menjadi solusi yang permanen, karena dasar sungai akan kembali tertutup oleh sedimen dari proses pencucian galian $\mathrm{C}$ di daerah hulu Sungai Remu. Hal ini menjadikan sungai Remu rentan terhadap kejadian banjir tahunan akibat potensi sedimen akibat kegiatan penambangan galian $\mathrm{C}$ tersebut akan selalu ada.

\section{KESIMPULAN}

Berdasarkan hasil pengamatan di atas, di ambil kesimpulan bahwa perancangan atau pembuatan drainase di Kota dan Kabupaten Sorong harus di perlebar atau dikeruk. Karena kondisi saluran pada drainase sudah tidak dapat menampung debit banjir atau perlu adanya pengerukan sedimentasi agar drainase bisa menampung kapasitas debit banjir. 


\section{DAFTAR PUSTAKA}

1. Fauzan, A., \& Pristianto, H. (2017). STUDI KELAYAKAN KAPASITAS TAMPUNG DRAINASE JALAN FRANS KAISEPO KELURAHAN MALAINGKEDI KOTA SORONG. RANCANG BANGUN, 3(1).

2. Wardoyo, A. (2017). TINJAUAN SISTEM DRAINASE JALAN GABUS DAN JALAN TAWES TUGU MERAH KABUPATEN SORONG.

3. Pristianto, H. (2018). Identifikasi Tinggi Genangan Banjir Di Das Remu Berdasarkan Kejadian Banjir Tahun 2006-2008.

4. Pristianto, H., Amri, I., \& Rusdi, A. (2014, May 9). Pedoman Penulisan Tugas Akhir Fakultas Teknik Universitas Muhammadiyah Sorong 2014. http://doi.org/10.17605/OSF.IO/4VTJM. 